\title{
La persona: alteridad y comunión. Perspectivas trinitaria, antropológica y eclesiológica en la teología de Ioannis D. Zizioulas
}

\author{
Jultán Ces ${ }^{*}$ \\ Pontificia Universidad Católica Argentina \\ juliances@uca.edu.ar \\ Recibido 12.03.2020/ Aprobado 15.04.2020 \\ DOI: $h$ ttps://doi.org/10.46553/teo.57.132.2020.p87-108
}

\section{RESUMEN}

La pregunta que guiará este artículo será cómo conciliar expresiones tan diversas como alteridad y comunión en la persona desde una perspectiva trinitaria, antropológica y eclesiológica. ¿No estamos ante expresiones que se excluyen mutuamente? ¿Es posible plantear un vínculo entre ambos vocablos? Para dar respuesta a tal interrogación recorreremos junto a I. Zizioulas el camino que nos llevará a afirmar que ambos términos se implican mutuamente reclamándose uno a otro.

Palabras claves: Alteridad; Comunión; Persona; Trinidad; Iglesia.

\section{The Person: Otherness and Communion. Trinitarian, Anthropological and Ecclesiological Perspectives in the Theology of Ioannis D. Zizioulas}

\section{ABSTRACT}

The question that will guide this article will be how to reconcile such diverse expressions as alterity and communion in the person from a trinitarian, anthropological and ecclesiological perspective. Are not we expressions that are

- El autor es profesor de Teolgía en la UCA (Facultades de Ciencias Económicas, Psicología y psicopedagogía, Medicina) y de Antropologogía Filosófica y Misterio de Dios en el Instituto Superior Nuestra Señora de las Nieves. 
mutually exclusive? Is it possible to make a link between both words? In order to answer this question, we will walk alongside I. Zizioulas the path that will lead us to affirm that both terms implicate each other by claiming one another.

Keywords: Alterity; Communion; Person; Trinidad; Church.

\section{Introducción}

El presente artículo aborda el estudio de la persona como «alteridad en comunión» $\mathrm{y}$ "comunión en alteridad» a la luz de las investigaciones de I. Zizioulas ${ }^{1}$ expuestas, recopiladas y publicadas en dos de sus obras de mayor envergadura: «El ser Eclesial. Persona, comunión e Iglesia» ${ }^{2}$ y "Comunión y alteridad. Persona e Iglesia». ${ }^{3}$ Si bien desarrolla sus estudios desde el lugar específico de teólogo ortodoxo, podemos afirmar que su reflexión es de puertas abiertas en un diálogo constante y desde un horizonte de comunión con la filosofía y la teología occidental.

Su propuesta en torno a lo trinitario, antropológico y eclesial sugiere una praxis donde la integración de lo diverso demuestra la valoración de cada persona por el mero hecho de existir como otro y no por sus posesiones. Las diferencias personales no implican un rasgo negativo que llevan a la división, sino todo lo contrario: un aporte positivo y peculiar que posibilita la comunión. Sin diversidad solo hay uniformidad. De ahí que el interés por investigar el concepto de persona a partir de las claves alteridad y comunión puede ofrecer un aporte válido tanto a la Iglesia como a la sociedad.

1 Este escrito surge a partir de la Disertación escrita para obtener el grado de Licenciatura en Teología con especialización en Teología Dogmática presentada en la Facultad de Teología de la Universidad Católica Argentina: Julián Oscar Ces, «La persona: alteridad y comunión. Perspectivas trinitaria, antropológica y eclesiológica en la teología de loannis D. Zizioulas», (Tesis de Licenciatura, Universidad Católica Argentina, Facultad de Teología, 2013), https://repositorio. uca.edu.ar/handle/123456789/545).

2 Ionnis D. Zizioulas, El ser eclesial. Persona, comunión, Iglesia (Salamanca: Ediciones Sígueme, 2003). [En adelante SE].

3 Ionnis D. Zizioulas, Comunión y alteridad. Persona e Iglesia (Salamanca, Ediciones Sígueme: 2009). [En adelante CA]. 
En los pequeños o grandes mundos donde el hombre transcurre sus días el aporte que nos ofrece el teólogo puede ayudar a descubrir la importancia de lo diverso como riqueza y no simplemente para aprender a convivir, como si fuera una realidad a tolerar. Tanto en una sociedad plural como en una Iglesia rica en carismas y ministerios la comunión expresa el querer de Dios, «que todos sean uno» $(J n$ 17,21) para que el mundo crea. De este modo podrá forjarse una verdadera cultura del encuentro y del diálogo.

La primera sección de este artículo «Alteridad para la comunión» nos introduce en la descripción de tal concepto clave en relación al ser de la creación, a Dios, a la Iglesia y al hombre. Seguidamente, la sección segunda «Ser persona y ser otro» nos permitirá acceder a la cuestión ontológica de la persona y al lugar que el otro ocupa en la identidad del propio yo. La tercera sección «Hacia una comunión en alteridad» abordará la realidad comunional de la persona plasmada en la realidad eclesial. Por último, en la cuarta sección presentaremos la recepción de las propuestas del teólogo griego en sus puntos polémicos y a través de voces discordantes.

\section{Alteridad para la comunión}

Para I. Zizioulas la alteridad no es una realidad secundaria a la noción de ser sino un elemento primigenio y constitutivo del mismo, es decir, una categoría ontológica relacionada con otra categoría clave: la comunión. De este modo, afirmará que no hay alteridad sin comunión como tampoco comunión sin alteridad. Recorreremos aquí los ámbitos donde el autor se detiene para la comprensión ontológica de la alteridad: la creación, Dios, la Iglesia y el ser humano.

\subsection{Alteridad y ser en la creación}

La fe bíblica sobre la creación ex nihilo será el puntapié inicial del teólogo griego para plantear las dimensiones de alteridad 
y libertad como constitutivos del ser. Si el mundo es real, y no una manifestación de Dios al modo como lo concibe el monismo griego antiguo, ${ }^{4}$ será porque este modo divino de crear de la nada implica ontológicamente que el ser no procede del mismo ser. De lo contrario todo ente de la naturaleza no tendría una realidad diversa respecto del ser originante.

Dios es totalmente otro. La existencia del mundo haya su razón de ser en su voluntad: libertad y alteridad son interdependientes ${ }^{5} \mathrm{y}$, respecto de las criaturas, constituyen dos notas propias del Dios personal. He aquí una de las fermentaciones que presenta I. Zizioulas como reinterpretación de la ontología griega: hacer «depender el ser del mundo de la libertad personal». ${ }^{6}$

Sin embargo, esta ontología radical desde la alteridad y la libertad como constitutivos del ser, puede resultar riesgosa ya que se aproxima al extremo donde sólo está presente la «separación y la distancia $»^{7}$ total entre Dios y el mundo. Por esto, cabe preguntarse si existe alguna relación entre el Creador y su criatura. Para el teólogo griego, Dios y el mundo se unen en Cristo. La relación Dios-mundo es hipostática, en y a través de la persona del Hijo "porque en él, creado e increado se han unido, definitivamente sin división (adiairétôs) y sin confusión (asynchytôs)». ${ }^{8}$

\subsection{Alteridad y ser de Dios}

Afirmada la realidad de la alteridad y la comunión entre Dios y la creatura, es posible preguntarnos: ¿Cómo compaginar alteridad

4 Según I. Zizioulas, dicho monismo sostiene que el mundo guarda afinidad ontológica con Dios, y por lo tanto su acción creadora no sería libre sino por necesidad otorgándole identidad divina.

5 CA, 31.

$6 \mathrm{SE}, 53$

$7 \mathrm{CA}, 35$.

8 CA 326. 
y comunión en el ser de Dios? ¿Puede darse alteridad ontológica en Dios sin poner en juego por ello la unidad divina?

En primer lugar, la identificación de Dios con el Padre - afirmado en las Escrituras y en los credos primitivos-, aparece en los capadocios con la comprensión de la monarchía como indicativa de un arché en la existencia divina en el sentido de origen personal y ontológico. Consecuencia de esto, el único arché ontológico en la Trinidad es el Padre. Si Él es el único principio personal en Dios, ¿cómo será la relación con las otras Personas? Si el concepto de arché implica movimiento y si el Padre es el fundamento, la relación ha de ser causal: «E1 Padre será la causa de que las otras dos personas sean hipóstasis distintas». ${ }^{9}$ Por ser el Padre el origen del ser personal y de la libertad, queda constituido como el garante de la alteridad ontológica entablando relaciones constitutivas. De aquí que la sustancia divina posea un carácter relacional: el Padre es inconcebible sin el Hijo y el Espíritu. Por tanto el Padre no es causa de identidad sino de alteridad, ésta descansa en la persona y no en la sustancia.

En segundo lugar, retomando la idea de lo creado y su caducidad, ¿cómo superar dicha realidad? Aquí I. Zizioulas da un salto en la fe afirmando con San Pablo que la muerte ha sido vencida. «La supervivencia de la creación es el contenido ontológico de la cristología». ${ }^{10}$ En Jesucristo lo creado y lo increado se han unido sin división y sin confusión. Esta perspectiva de la Resurrección como confirmación de la cristología de Calcedonia es clave para comprender la dimensión histórica y temporal de la salvación. ${ }^{11}$ Por tanto, no

9 CA, 154-155.

$10 \mathrm{CA}, 55$.

11 Una de las objeciones planteadas a la formulación del concilio es la dificultad para precisar si Calcedonia habla del Jesús prepascual o del resucitado ya que «está ausente el dato bíblico primordial: el de la evolución de Cristo y, consiguientemente, el de la resurrección». Cf. José I. González Faus, «Relectura de Calcedonia. Las fórmulas de la dogmática cristológica» Estudios Eclesiásticos 46 (1971): 339-367 http://www.faculdadejesuita.edu.br/documentos/211112pSkLkJIn9dnxP.pdf. Por ello Zizioulas sostiene que la enseñanza de Calcedonia sobre la persona de Jesucristo pierde sentido si no está en relación con el problema de lo creado y la superación de la muerte. Si Cristo salva, es porque encarna en su persona la victoria sobre la muerte. $\mathrm{Cf}$. CA, 326 . 
es la naturaleza de lo creado, sino la resurrección del Señor, quién permite escapar de la corrupción de la muerte.

En tercer lugar, I. Zizioulas aborda dos tesis sobre el Espíritu Santo a partir del mismo Concilio: la realidad divina y la procedencia del Espíritu. Primeramente afirma la divinidad de la tercera persona como aquel que está «junto al Padre y al Hijo recibe una misma adoración y gloria». ${ }^{12} \mathrm{Al}$ proceder del Padre y distinto de Él, estamos situados en el ámbito de la alteridad. Al ser constituido como tal desde una relación causal existe distinción ontológica pero no división o separación con respecto a las otras personas de la Trinidad. Dicha causalidad fundamenta la comunión, gracias a la cual cada una de las Personas divinas son constituidas como tales. Buscando salvaguardar el principio personal, dirá que el fundamento último del Espíritu no es una sustancia sino es la persona del Padre, de quién procede. Esta realidad permite converger «en el espinoso tema en torno a la procedencia del Espíritu respecto al Hijo» ${ }^{13}$.

\subsection{Alteridad y ser en la Iglesia}

Al abordar la eclesiología, I. Zizioulas presenta dos modos posibles. Un primer acercamiento, desafortunado para él, considera las estructuras jerárquicas como centrales y necesarias, donde la alteridad es secundaria respecto a la unidad. Esta interpretación responde a una eclesiología cimentada en una teología trinitaria sustancialista donde la prioridad está en la sustancia y no en la persona, prevaleciendo lo «uno» sobre los «muchos». Como paradigma de esta corriente encontramos el modelo eclesiológico de J. Ratzinger y K. Rahner a partir de la obra conjunta ${ }^{14}$ referente a las

12 Heinrich Denzinger, Peter Hünermann, eds., El magisterio de la lglesia ${ }^{38}$, (Barcelona: Herder, 2000) 150 .

13 CA, 242

14 Karl Rahner y Joseph Ratzinger, Episcopado y primado (Barcelona: Herder, 20052) y en Joseph Ratzinger, Iglesia, ecumenismo y política (Madrid: Biblioteca de Autores Cristianos, $2005^{2}$ ). Destacamos también el debate entre J. Ratzinger y $W$. Kasper que tuvo su inicio en la objeción de éste a una afirmación de la Carta a los obispos de la Iglesia Católica acerca 
relaciones entre la Iglesia universal y las Iglesia locales, donde la unidad precede a la pluralidad y la sustancia a la existencia.

En cambio la propuesta de I. Zizioulas transitará otro camino: el ser eclesial ha de ser personal y no sustancial. «La única Iglesia es constituida por muchas Iglesias (...), sin que ninguna de ellas esté sujeta a otra como parte de ésta o de un conjunto, sino siendo cada una de ellas todo del todo». ${ }^{15}$ Por tanto, unidad y pluralidad, lo local y lo universal, deben coincidir.

\subsection{Alteridad y ser humano}

Si bien sobre este punto nos vamos a detener con mayor profundidad, cabe aquí adelantar algunas consideraciones centrales. Si I. Zizioulas tiene un modo de definir al ser humano, lo hará categóricamente indicando que es alteridad. ${ }^{16} \mathrm{El}$ punto de partida para dicha afirmación lo sitúa en la llamada que Dios le dirige a Adán. Por ello, no puede haber ser humano a menos que haya un Otro que dé lugar a la llamada, en tanto que el hombre existe gracias a un llamado recibido desde afuera. Este entorno permite comprender la existencia del hombre como don y tarea.

Dicha llamada enlaza tres escenarios interdependientes y constitutivos del ser personal: relación (toda llamada involucra a dos sujetos, quien llama y aquel que es llamado, implicándose mutuamente en un vínculo dialogal), libertad (le permite al hombre distanciarse de la propia naturaleza para aceptar o rechazar todo aquello que le es dado) y alteridad (como unicidad).

de algunos aspectos de la comprensión de la Iglesia como comunión (1992). Mientras que J. Ratzinger sostiene la preexistencia de la Iglesia universal como realidad anterior y ontológica en desmedro de la Iglesia particular, W. Kasper afirma la simultaneidad de la Iglesia universal y cada iglesia individual.

$15 \mathrm{CA}, 187$.

$16 \mathrm{CA}, 57$. 


\section{Ser persona y ser otro}

La cuestión versará en torno al siguiente interrogante: ¿somos persona o poseemos una persona? Situados en el ámbito del poseer o del ser, la persona pasaría a ser una cualidad añadida o un elemento constitutivo del ser. Para nuestro autor el hito filosófico decisivo fue la identificación de la «hipóstasis» con la «persona». ${ }^{17}$ Esta reinterpretación de la ontología por parte del pensamiento griego se debió a dos fermentaciones que se dieron a luz en la teología patrística. En primer lugar, pasar de la necesidad cosmológica a la libertad del mundo, y en segundo lugar, la identificación del ser de Dios con la persona como principio ontológico.

\subsection{De la existencia biológica a la existencia eclesial}

Uno de los aportes patrísticos es la aplicación de los conceptos filosóficos al plano de la fe. Así es posible proponer teológicamente al hombre según dos modos: la hipóstasis de la existencia biológica y la hipóstasis de la existencia eclesial.

«La hipóstasis de la existencia biológica está constituida por la concepción y el nacimiento del hombre». ${ }^{18}$ Sin embargo, la muerte la constituye en una realidad trágica surgiendo el interrogante sobre una posible salvación. Sólo el nuevo nacimiento a través de la gracia bautismal despoja al hombre de su dimensión trágica y forja de este modo la hipóstasis de la existencia eclesial. Esta nueva hipóstasis ha de estar constituida por una realidad ontológica que no sufra la condición de creaturidad. Es la persona del Hijo quien lleva a cabo la auténtica personeidad, haciendo de ella la hipóstasis de la persona para todos, pudiendo así el hombre subsistir gracias a su relación con Cristo. 
Ahora bien, para expresar la mutua relación entre las hipóstasis -biológica y eclesial- será necesaria una nueva categoría ontológica que exprese no sólo aquello que el hombre es, sino aquello que será: «hipóstasis paradójica que tiene sus raíces en el futuro y sus ramas en el presente». ${ }^{19}$ Será la hipóstasis eucarística quién permita al hombre alcanzar su ser no de lo que es ahora sino de lo que será en el futuro, siendo la resurrección de Cristo, prenda y señal de aquella realidad pregustada en cada eucaristía.

\subsection{La persona como cuestión ontológica}

El teólogo griego afirma la ultimidad y prioridad ontológica desde el siguiente presupuesto: el ser es causado, siendo esta causalidad ontológicamente absoluta y primaria. «Este principio de causalidad personal del ser significa que la particularidad en ontología ha de entenderse como causativa y no derivativa». ${ }^{20}$ Esta realidad conduce a un escenario relacional donde las nociones de «éxtasis» ${ }^{21}$ e «hipóstasis» ${ }^{22}$ serán claves para representar los matices del ser personal. Gracias a ellos es posible manifestar como la realidad personal no es una cualidad añadida sino constitutiva del ser.

La identificación de la «hipóstasis» con lo personal remite a que tal cuestión ontológica no encuentra respuesta en el horizonte de una auto-existencia. Cada persona es un don que proviene de otro, resultado del amor y de la libertad. Por tanto, ontológicamente, las personas son donantes y receptoras de identidad personal. Tal realidad encuentra su fundamento en el misterio trinitario: «El in-causado que causa alteridad. Esto convierte al Padre en fuente última de donación del ser personal». ${ }^{23}$

21 Como apertura del ser hacia la comunión cf. CA, 267.

22 Para el autor: persona, modo de existencia única e irrepetible. Cf. CA, 268.

$23 \mathrm{CA}, 184$. 


\subsection{El lugar del otro ante el propio yo}

¿Cuál es el lugar decisivo que el otro ocupa en la determinación de la identidad del propio yo? Nuestro autor hará referencia a dos representantes de la filosofía de la relación, ellos son Martín Buber y Emmanuel Lévinas, con quienes se sienta a la mesa del diálogo crítico entablando un coloquio enriquecedor.

De M. Buber valora el modo de presentar la constitución del ser desde la perspectiva del otro como co-constitutivo. Pero, sin embargo, I. Zizioulas sostiene que aún sigue conservando la primacía del yo sobre el otro, particularmente al analizar los dos tipos de relaciones que todo ser humano puede establecer, Yo-Tú y YoEllo, ${ }^{24}$ dirá que es el yo quien decide por una u otra relación. De este modo, el tú termina dependiendo de las intenciones del yo para existir como un Tú o un Ello.

Desde la perspectiva de E. Lévinas estima el paso que da para la comprensión del otro constituido como tal desde una alteridad absoluta que no se deriva, engendra o constituye desde otra existencia. Pero también plantea una cuestión sin resolver: la reconciliación entre alteridad y comunión ya que el filósofo no acepta la comunión al considerarla una amenaza para la alteridad. De aquí que su planteo será el de la separación y la distancia y no el de la relación. ${ }^{25}$

Para I. Zizioulas pensar la alteridad significa partir de la realidad: el hombre vive una existencia caída gracias al rechazo del Otro por parte de Adán. Consecuencia de tal ruptura, la alteridad se convierte en una amenaza -como si del enemigo se tratase- generando división. Por tanto, cuando la diferencia se identifica sin más con la división, queda abolida la relacionalidad y, como derivación, toda posibilidad de comunión.

24 Cf. Martin Buber, Yo y Tú (Buenos Aires: Ediciones Lilmod, 2006), 11.

$25 \mathrm{Cf}$. Emmanuel Lévinas, Totalidad e infinito: ensayo sobre la exterioridad (Salamanca: Ediciones Sígueme, 1997), 299. 
El rechazo de Adán a Dios trajo como consecuencia no sólo el surgimiento del yo como lo ontológicamente primordial de la existencia, sino también la subordinación de la hipóstasis a la naturale$\mathrm{za}$, acarreando el conflicto entre el ser humano y su propia naturaleza. Tal conflicto surge porque en el hombre la naturaleza precede a la persona, ${ }^{26}$ todos nacemos como seres particulares a partir de las leyes naturales comunes a todos los hombres. Así lo general precede ontológicamente a lo particular.

Dicho conflicto ontológico entre persona y naturaleza se halla en el fundamento del ser, lo determina y se pone de manifiesto particularmente en dos momentos decisivos y sucesivos: el nacimiento y la muerte. Por tanto, el camino a recorrer será la hipostatización de la naturaleza de acuerdo a su fin, o sea, la naturaleza que existe en la hipóstasis del Logos divino que reúne todos los particulares en el Uno. Esta cuestión revela que un ser particular sólo podrá vivir cuando su meta propia, no sea su naturaleza o cualquier otra cosa, sino la persona del Otro, quien puede hipostasiar el particular llevándolo al estado de ultimidad ontológica. Sólo de este modo evitará que su particularidad sea absorbida por lo general experimentando la muerte.

Finalmente comprender el ser desde la categoría del don, admite suponer que la existencia de un ser presupone al otro. Por lo tanto, la alteridad es constitutiva del ser ya que la causalidad contiene una importancia decisiva. Aquí unicidad y alteridad se dan cita: «Los seres existen como particulares en cuanto don del otro que les asegura una identidad estableciendo con ellos una relación única». ${ }^{27}$ 


\section{Hacia una comunión en alteridad}

Una de las afirmaciones claves de I. Zizioulas, respecto a la ontología de Dios revela lo siguiente: «El ser de Dios es un ser relacional». ${ }^{28}$ Por tanto, Dios es un acontecimiento de comunión. Esta realidad permite recuperar la categoría de perijóresis. Categoría antiguan y nueva, forjada por los padres de la Iglesia y retomada por figuras contemporáneas pertenecientes a ambas tradiciones teológicas.

\subsection{De la teología a la eclesiología}

Pensar la Iglesia desde una síntesis entre los componentes cristológicos y pneumatológicos permite conjugar los elementos institucionales y los carismáticos en tanto que «Cristo in-stituye y el Espíritu con-stituye» ${ }^{29}$ a la Iglesia. Expresión de esto lo encontramos en los siguientes binomios: un solo cuerpo y muchos miembros, jerarquía y carismas; uno y muchos, Iglesia universal e Iglesia local, etc.

Así «la Iglesia no es simplemente una institución. Es un «modo de existencia», una forma de ser ${ }^{30}$ que da origen a la comunidad constituida por los bautizados quienes han experimentado la conversión fundamental permitiendo el paso decisivo del individualismo a la personeidad. Así, la asamblea litúrgica es un paradigma de la comunión eclesial ya que integra todos los ministerios como elementos constitutivos y a todos los miembros «que se reúnen como huéspedes de una casa particular». ${ }^{31}$

Una certeza digna de destacar es la siguiente: «No existen personas «no ordenadas» en la Iglesia». ${ }^{32}$ Es sumamente sugerente tal afirmación ya que por el Bautismo toda persona queda incorporada 
a la comunidad eclesial, ocupando en ella un determinado orden en la vida de la comunidad: el orden de los laicos. ${ }^{33}$

\subsection{Iglesia local e Iglesia Universal}

Las consecuencias de una eclesiología constituida desde los aportes de las personas de Cristo y del Espíritu configuran un rostro eclesial marcado por la comunión, donde lo local y la universal se implican mutuamente y no pueden darse sino en simultaneidad: no hay prioridad de lo universal sobre lo local, ni de lo local sobre lo universal. Así como hay un solo Dios, también hay una Iglesia, pero ésta encuentra su expresión en la comunión de las Iglesias locales. Como en las personas divinas, aquí también las categorías de comunión y unidad coinciden en el ser de la Iglesia.

La institución visible que manifiesta la unidad eclesial tiene que expresar la comunión, y por lo tanto no puede ser autosuficiente ni anterior al acontecimiento de comunión. Así, «toda noción piramidal desaparece de la eclesiología». ${ }^{34}$ Para la teología ortodoxa, la institución canónica que respalda tal postulado es el sínodo, donde los «muchos» (obispos o Iglesias locales) no pueden hacer nada sin el «uno» (institución de unidad) y, simultáneamente, el «uno» no puede hacer nada sin los «muchos».

Desde la simultaneidad entre lo local y lo universal es posible afirmar que la Iglesia local no ha de ser absorbida por lo universal, pero tampoco las estructuras que aseguran la comunión entre las Iglesias locales deben convertirse en una superestructura por sobre la Iglesia local. «Todas las estructuras destinadas a facilitar la universalidad de la Iglesia crean una red de comunión de Iglesias, no una nueva forma de Iglesia». ${ }^{35}$ 


\subsection{Mística eucarística}

La expresión por excelencia de la comunión se encuentra en la eucaristía. Ella hace a la Iglesia reuniendo a todos los hombres y los incorpora a Cristo formando así su cuerpo. ${ }^{36}$ En cada celebración la diversidad de miembros y ministerios de la comunidad reflejan la vida y la riqueza de Dios. Un Dios que es comunión de amor.

Por ello, la eucaristía se vuelve el ámbito propicio para la afirmación de los otros como un don para mí y a su vez nos permite expresar la acción de gracias por el don del Otro. Ella invita al agradecimiento, valoración y afirmación de los otros como tales -más allá de sus cualidades morales o naturales- contrariamente a como han expresado la filosofía nihilista, para quién la otredad es mi propio infierno y mi pecado original, en palabras de Sartre. El otro, lejos de amenazar la propia libertad ontológica la erige como seres particulares. «Permaneciendo otro y constituyéndonos como otros, el otro confirma nuestra alteridad, nuestra libertad ontológica para ser otros». ${ }^{37}$

\section{Recepción de las propuestas de I. Zizioulas}

Al llegar al fin de este recorrido se puede afirmar que el hilo conductor es una ontología relacional que, proveniente de la teología trinitaria, establece la alteridad y la comunión como la base firme donde apoyar tanto la noción de la persona como la de la Iglesia. ${ }^{38}$ Nos dedicaremos aquí a presentar los puntos críticos de su teología como la valoración de sus aportes significativos.

36 Cf. Eleuterio Fortino, «La "Communio-Koinonía» en el diálogo católico-ortodoxo», en Eclesiología. 30 años después de «Lumen Gentim», dir. Pedro Rodriguez (Madrid: Ediciones Rialp, 1994), 220.

37 CA, 119.

38 Cf. Fernando Rodríguez Garrapucho, Recensión a Comunión y alteridad. Persona $e$ Iglesia, lonnais Zizioulas (Salamanca: Sígueme, 2009), 182. 


\title{
4.1. Puntos polémicos
}

\subsubsection{El Padre: principio y origen en la Trinidad}

Habiendo abordado la problemática de concebir a Dios como sustancia o como sujeto y optando por la comprensión de un Dios personal en la teología de I. Zizioulas, aquí nos dedicaremos a otro interrogante: ¿Cuál es el orden de las personas en la Trinidad? ¿Quién es el primero? El teólogo griego sostiene desde Jn 14, 28 y desde el plano ontológico que «el Padre es el mayor». ${ }^{39}$ Sin embargo hay que afirmar que se trata de una prioridad causal pero no significa una diferencia sustancial. ${ }^{40}$

Identificar la unidad divina con el Padre, como origen fontal, puede llevar a una comprensión modalista o subordinacionista. Con el fin de evitar tales riesgos, la persona del Padre ha de ser comprendida desde una perspectiva relacional: «El Padre es fuente y origen por la recepción de la divinidad y aceptación del Hijo y el Espíritu». ${ }^{41}$ Será la dimensión relacional de la persona quién resuelve los puntos de conflictos en la cuestión de la taxis trinitaria. Así también lo entendió I. Zizioulas al presentar al Padre como el iniciador del movimiento en Dios, estableciendo así un orden inmanente y económico:

\begin{abstract}
«La co-emergencia de la naturaleza divina con la existencia trinitaria iniciada por el Padre implica que éste también adquiere, por decirlo de algún modo, la divinidad sólo en tanto el Hijo y el Espíritu son (no es concebible como Padre sin ellos), es decir sólo cuando la naturaleza divina es poseída por los tres. Así pues, el Padre, es más grande que el Hijo (y el Espíritu) no por naturaleza, sino por el modo (el cómo) en que la naturaleza existe, eso es, en la hipostización de la naturaleza. El orden trinitario y la causalidad protegen (no amenazan) la igualdad y la plenitud de la divinidad de cada persona». ${ }^{42}$
\end{abstract}

39 CA, 183.

40 Cf. Francisco Sales Casanovas, «El concepto de persona en la teología de loannis D. Zizioulas». (Tesina de licenciatura, Universidad Pontifica Comillas, Facultad de Teología, 2010) 281, http://www.mundomarianista.org/wp-content/uploads/Texto-a-editar.pdf [consulta: 25 de agosto 2015$] 281$.

41 Gonzalo Zarazaga, Dios es comunión. El nuevo paradigma trinitario (Salamanca: Secretariado Trinitario, 2004), 277.

42 CA, 179. 
Que el Padre sea principio y origen «en» la Trinidad no significa buscar algo previo a la relación con el Hijo y al Espíritu Santo. Si así fuera primero «sería» antes de ser Padre. La referencia al Hijo y al Espíritu llegaría en un segundo momento. La ausencia de origen del Padre, «está en relación con la generación del Hijo y la espiración del Espíritu Santo». ${ }^{43}$ Por tanto no se puede oponer divinidad fontal y paternidad. La posición primordial que el Padre ocupa en la Trinidad no es previa a la relación con el Hijo y el Espíritu Santo. Principio fontal y relación constituyen la persona del Padre.

\subsubsection{La naturaleza en I. Zizioulas}

Un punto crítico en la teología de I. Zizioulas es el significado que aplica al concepto de naturaleza. El hombre como ser creado se halla privado de cualquier propiedad que no sea creada. En esto radica su existencia trágica: naturalmente el hombre está condenado a la muerte. Aquí es posible vislumbrar una cierta comprensión negativa de la naturaleza humana: ¿no se contradice con la bondad que Dios imprimió al crear al hombre afirmando que era muy bueno? En la tradición occidental la naturaleza humana también ha sido comprendida en diversos horizontes, donde rasgos positivos y negativos se han dado cita. Es el caso de San Agustín quién señala su bondad y belleza por ser obra del creador pero a su vez corrompida por el pecado original convirtiéndose en natura peccatrix que sólo puede ser restituida a su autenticidad por la gracia.

De este modo, la naturaleza humana puede concebirse como buena en sí misma o admitirla como corrompida y necesitada de redención. Desde la economía de la salvación, es factible alinear el pensamiento de I. Zizioulas en la segunda opción. Tomando como punto de partida la caída de Adán, dicho autor incorpora en su pensamiento el paso de la existencia biológica a la eclesial justamente para dar cuenta que el hombre por sí mismo en su condición natural

43 Luis Ladaria, La Trinidad como misterio de comunión (Salamanca: Secretariado Trinitario, 2002), 145 . 
no puede trascender su existencia. Sólo en la apertura y en la relación con el Otro puede encontrar vida en abundancia.

Creados a imagen y semejanza sabemos que la naturaleza del hombre no es divina en sí misma, sin embargo es querida y deseada por Dios. Que la existencia del hombre se comprendida como don del Otro, ¿puede conducir a pensar que el teólogo griego desprecie su naturaleza creada? Desde la ontología personal propuesta por él, es posible postular que la naturaleza es inseparable de la gracia, y así en la persona del Hijo, tal naturaleza caída ya no impone sus limitaciones.

\subsubsection{La persona}

Entre los aportes a destacar sin duda la concepción de persona como «alteridad en comunión y comunión en alteridad» ${ }^{44}$ se sitúa en un lugar privilegiado y expresa una síntesis válida de su teología abarcando e involucrando tanto las perspectivas trinitarias y eclesiológicas como las antropológicas y filosóficas.

El ser personal emerge en el contexto relacional, se trata de un «yo» que existe referido a un «tú» que afirma su existencia y alteridad. Las circunstancias de nuestra cultura, signada por el individualismo, el hedonismo y la autosuficiencia, muestran que vivimos una época donde la comunión con el otro cada vez es más compleja, tanto en el ámbito eclesial como secular. Tal vez la propuesta de la existencia personal desde la clave receptiva permita descentrar al hombre de su egología ${ }^{45}$ para descubrir que todo individuo nace de una llamada y se orienta hacia una respuesta.

La alteridad de la persona no puede ser rechazada a causa de las diferencias naturales, sexuales, raciales, sociales, étnicas y/o morales. Toda persona al ser libre y misteriosa, en cuanto habitada 
por el Espíritu y miembro del cuerpo de Cristo, es portadora de una dignidad fundada en Dios, al crearnos a su imagen y semejanza.

\subsubsection{La Iglesia}

Delineamos algunos puntos que han de ser tenidos en cuenta para una eclesiología de comunión que quiera trasparentar en su existencia el ser de Dios. La expresión máxima y fundamental se encuentra en la eucaristía. Allí se dan cita la alteridad y la comunión en tanto que supone la aceptación y confirmación del otro.

I. Concebir a la persona como hipóstasis y éxtasis en la teología de I. Zizioulas encuentra su paralelo en la existencia discipular misionera del cristiano. Tanto en el acontecimiento de Aparecida, como en las homilías del entonces Cardenal Bergoglio y posteriormente en el magisterio de Francisco, se encuentra la misma constante tanto en el plano personal como eclesial. El cristiano y la Iglesia no se entienden si no es desde la perspectiva del encuentro y la salida. Así lo expresó en Evangelii Gaudium invitando a la comunidad eclesial a primerear, involucrarse, acompañar, fructificar y festejar. ${ }^{46}$

II. Pensar, soñar y trabajar por una Iglesia que viva desde el prisma de la comunión en la alteridad invita ahora a los creyentes a detenerse en la dimensión ministerial propuesta por el ortodoxo griego, sobre todo referido a dos puntos clave: el orden de los laicos y el primado. Teniendo en cuenta que para este autor «no existen personas no ordenadas en la Iglesia», ${ }^{47}$ tal afirmación señala una valoración sugerente del estado laical, muchas veces definido por vía negativa como no-consagrado o no-ministro ordenado. Este aporte permite afirmar su vocación propia como riqueza en orden a la comunión desde la relacionalidad de todos los carismas y ministerios.

III. Otra de las manifestaciones de la comunión eclesial es la sinodalidad expresada en la eucaristía, los ministerios y el primado 
autoridad. Aquí la clave relacional juega un rol determinante. Tanto la sinodalidad como el primado son interdependientes y «constituyen la columna vertebral del gobierno y organización de la Iglesia».48 Así lo ha expresado el Documento de Rávena de la Comisión Mixta internacional para el diálogo teológico entre la Iglesia de ambas tradiciones. ${ }^{49}$

La sinodalidad no es anterior a la comunión ni autosuficiente, como tampoco el primado se entiende sin los muchos. Se trata de una reciprocidad activa como bien lo ha explicitado el CV II con la fórmula una cum Patribus. La autoridad es ejercida por el obispo de Roma unido con todos los obispos. Por tanto la sinodalidad será el camino propicio para que el primado del obispo de Roma sea aceptado ecuménicamente, ya que no se tratará de un primado de dominio sino de servicio a la unidad y a la edificación de la Iglesia. ${ }^{50}$ Los encuentros entre el actual Pontífice y el metropolita de Pérgamo como los puntos de contacto entre el pensamiento del teólogo y el obispo de Roma, son una expresión válida del camino a recorrer hasta lograr «que todos sean uno» $\left(\right.$ Jn 17, 21). ${ }^{51}$

48 Bartolomé I, La Sagrada Escritura en la tradición ortodoxa. Alocución del Patriarca Ecuménico Bartolomé I al concluir las / Visperas del domingo XIX en la Capilla Sixtina [en línea], http://www.vatican.va/news_services/press/sinodo/documents/bollettino_22_ xii-ordinaria-2008/04_spagnolo/b30_04.htm I\#DISCURSO_DEL_PATRIARCA_ECUMÉNICO_ BARTOLOMÉ_I [Consulta: 20 de octubre 2016].

49 Cf. Comisión mixta internacional para el diálogo teológico entre la Iglesia católica romana y la Iglesia ortodoxa, Documento de Rávena, [en línea] 2007 http://maitequeseamosunopraqueelmundocrea.blogspot.com.ar/2013/1 1/documento-de-ravena-entre-lasiglesias.html, [consulta: 19 de diciembre 2015] 43.

50 Cf. Francisco, «Discurso del Santo Padre Francisco en la conmemoración del 50 aniversario de la Institución del Sínodo de los Obispos», Boletín eclesiástico del Arzobispado de Buenos Aires 578 (2015): 473.475.

51 Entre ellos, cf. Francisco, Discurso del Santo Padre Francisco a una delegación del Patriarcado ecuménico de Constantinopla. Sábado 28 de junio 2014, https://w2.vatican.va/ content/francesco/es/speeches/2014/june/documents/papa-francesco_20140628_patriarcatoecumenico-costantinopoli.html [Consulta: 11 de noviembre 2015 ] y Cf. I. Zizioulas, El diálogo teológico con los católicos en riesgo de fracasar (Entrevista) [en línea]. 


\subsection{Voces discordantes}

La teología de nuestro autor ha resonado en distintos ambientes, tanto Orientales como Occidentales, alcanzando diversos ecos con voces críticas a su pensamiento. Presentaremos aquí brevemente dos perspectivas en contraposición.

L. Turcescu en su artículo ««Person» versus «Individual», and other modern misreadigs of Gregory of Nissa ${ }^{52}$ propone investigar si el concepto de persona de los Padres Griegos le da sustento a I. Zizioulas para su tesis. Para aquél, el teólogo ortodoxo no representa en sus postulados la teología Capadocea, en tanto que el complejo de cualidades poseídas por los individuos que I. Zizioulas niega al hablar de la persona están presente en los Padres Capadoceos. Ellos intercambian individuo y persona ya que aún apenas emerge la distinción de ambos conceptos, por tanto utilizan prosopon e hipostasis como sinónimos al hablar de la persona.

De esta manera L. Turcescu dirá que I. Zizioulas, más que sustentarse en la teología de los padres, está influenciado por pensadores modernos al proponer el concepto de persona, sobre todo en M. Buber y J. Macmurray's afirmando que ha tratado de darle a la concepción relacional de la persona un contexto patrístico cuando en realidad ha utilizado para ello pensadores del siglo XX.

Frente a tales postulados sale al paso A. Papanikolaou ${ }^{53}$ preguntándose si I. Zizioulas es un existancialista disfrazado como lo caracteriza L. Turcescu. En primer lugar dirá que éste no tiene en cuenta otros Padres que estudia I. Zizioulas, como Gregorio de Nazianzo, decisivo en la ontología relacional. Por otro lado, es el mismo teólogo griego quien expresa que la comprensión trinitaria difiere de los sistemas filosóficos o pensadores modernos como M. Buber.

52 Lucian Turcescu, "Person" versus «Individual», and Other Modern Misreadings of Gregory of Nyssa», Modern Theology 18 (2002): 527-539.

53 Aristotle Papanikolaou, «Is John Zizioulas an existentatialist in disguise? Response to Lucian Turcescu», Modern Theology 20 (2004): 601-607. 
Para I. Zizioulas el corazón del discurso teológico es la comunión divina, la monarquía del Padre enraizada en la experiencia divina, en la Eucaristía, cuerpo de Cristo y en el Espíritu. De este modo, la ontología personal es la más adecuada manera de expresar el realismo de la comunión divina. La cuestión crucial para A. Papanikolaou será si la teología trinitaria que afirma la monarquía del Padre es la única manera de fundamentar una ontología personal y si tal ontología corrige y justifica las comprensiones modernas filosóficas de persona.

\section{Conclusión}

Alteridad y comunión han sido los dos ejes que se desarrollaron en este artículo sobre la ontología personal en la teología de I. Zizioulas cuyo objetivo ha sido adentrarnos en el misterio de la persona desde las claves trinitarias, antropológicas y eclesiológicas. Mucho se ha escrito sobre la persona a lo largo de la historia, sin embargo la perspectiva que recorre el autor investigado realiza un aporte singular que permite integrar en toda existencia las claves de lo diverso y lo común en su mutua implicación y relación.

Solo una Iglesia que sea «casa y escuela de comunión» ${ }^{54}$ podrá expresar el ser de Dios, de la persona y de la Iglesia. La perijóresis será la forma más adecuada para acoger la invitación que Dios nos propone para que cada uno de nosotros tomemos parte en la danza del amor íntimo de la Trinidad dirigiéndose unos a otros en el amor. De esta manera podremos valorar la riqueza del entramado de relaciones que en la cotidianeidad de la vida se dan cita en todos los ámbitos y situaciones existenciales de las personas.

Este escenario perijorético nos invita a valorar como riqueza lo diverso, en tanto que las diferencias no deben orientarnos hacia la división, sino todo lo contrario, desde ellas mismas deben direccio- 
narnos a una la realidad comunional. Este sendero a recorrer parte de la riqueza singular que cada uno puede aportar desde su singularidad al bien común. Realidad que ha de ser vivenciada tanto en la sociedad plural como en la Iglesia rica en carismas y ministerios, descubriendo que todos estamos llamados a realizar la nuestra existencia personal desde la propia alteridad pero hacia la comunión, desde una perspectiva dialógica de integración que aúna tanto los aportes filosóficos como teológicos.

\section{Bibliografía}

Bobrinskoy, Boris, El misterio de la Trinidad. Salamanca: Secretariado Trinitario, 2008.

Ferrara, Ricardo, El misterio de Dios. Correspondencias y paradojas. Salamanca: Ediciones Sígueme, 2005.

Greshake, Gisbert, El Dios uno y trino. Una teología de la Trinidad. Barcelona: Herder, 2001.

Hemmerle, Klaus, Tras las huellas de Dios: ontología trinitaria y unidad relacional. Salamanca: Ediciones Sígueme, 2005.

Pié-Ninot, Salvador, Eclesiología, La sacramentalidad de la comunión cristiana. Salamanca: Ediciones Sígueme, 2006.

Ratzinger, Joseph, Iglesia, ecumenismo y política. Madrid: Biblioteca de Autores Cristianos, 2005.

Uríbarri Bilbao, Gabino, Monarquía y Trinidad. Madrid: Universidad Pontificia Comillas, 1996.

Zizioulas, Ionnis D, El ser eclesial. Persona, comunión, Iglesia. Salamanca: Ediciones Sígueme, 2003.

Zizioulas, Ionnis D, Comunión y alteridad. Persona e Iglesia. Salamanca: Ediciones Sígueme, 2009. 